\title{
GENITAL AMBIGUITY AND ASSIGNMENT OF SEX - A CASE REPORT
}

\author{
ATM MOWLADAD CHOWDHURY ${ }^{1}$, SHAFIQUR RAHMAN ${ }^{1}$, MOHAMMAD ABDUL AZIZ1 ${ }^{1}$, MIRZA MAHBUBUL \\ HASAN ${ }^{1}$, NURUNNAHAR HAPPY ${ }^{2}$
}

${ }^{1}$ Dept. of Urology, BIRDEM General Hospital, ${ }^{2}$ Dept. of Plastic and Reconstructive Surgery, Dhaka Medical College Hospital

\begin{abstract}
:
A 15 year patient having 46XX karyotype, along with well developed male type of external genitalia and developing breast reported to us. It was assessed on all technical and judicious points and the male sex was assigned.
\end{abstract}

Bangladesh J. Urol. 2015; 18(2): 98-99

\section{Case summary}

A 15 year old child was being reared as a male baby as identified by his well developed male external genitalia. But parents became suspicious and scared when he started developing breast for last two years. His physical examination revealed female type of developing breast, age compatible development of phallus, normal looking scrotum where left hemi-scrotum was empty but right hemi-scrotum contains two separate structures unlike testis. He had proximal penile hypospadias and corrective surgery was done when he was 8 years. His karyotype was 46XX. Ultrasound scan shows no uterine or ovarian structure in abdomen but in right scrotum there were two structures mimicking rudimentary uterus and one ovary. He experienced bouts of scrotal pain and swelling in months apart which used to sustain for 2-3 days. It provokes the suspicion of menstrual episode. His estrogen, progesterone, $\mathrm{FSH}$ and LH were at lower level of female pubertal values. Serum testosterone level was very low. FNAC of scrotal structuredid not have testicular proof.

\section{Treatment:}

Technical feasibility and ethical aspect of assignment of sex were assessed and co-related. Neither a functional male nor a female sex is possible. He was reared as male baby and as the parents desired him a male, bilateral mastectomy and removal of all nontesticular structures from scrotum were planned. In steps of surgical procedure, cystoscopy showed elongated prostatic utricle (homologous to vagina) but no continuation above into a uterine cervix. Then scrotal exploration was performed that revealed under developed uterus with one fallopian tube and one small ovary having sign of ovulation, uterus was devoid of cervix and there was no continuity down to vagina. All of these structures were removed and histology confirmed the named structures. Subcutaneous mastectomy was done and histology confirmed female breast. Post-operative recovery was smooth. Then the patient was referred to pediatric endocrinologist for male hormone supplementation.

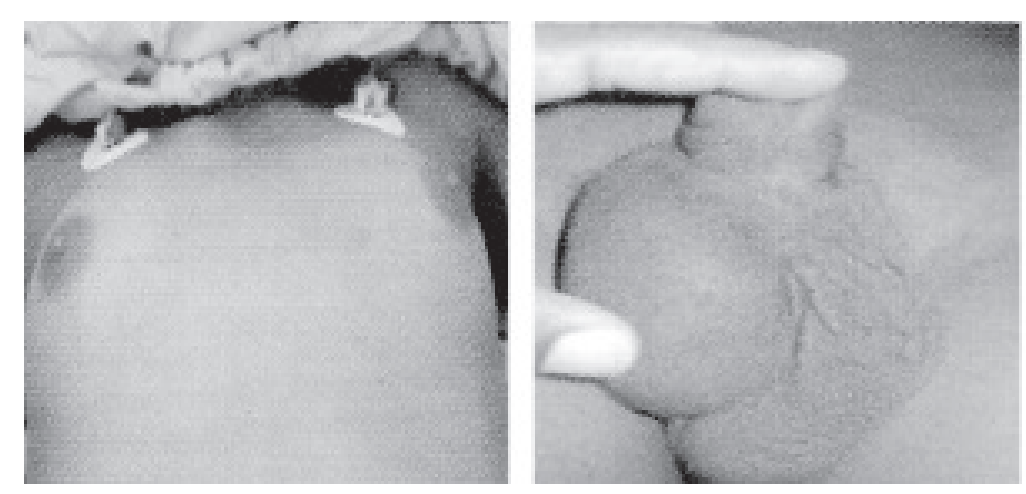

Fig.-1: Preoperative

Correspondence: ATM Mowladad Chowdhury, Associate Professor of Urology, BIRDEM, Dhaka. E-mail: drmawladad@ yahoo.com

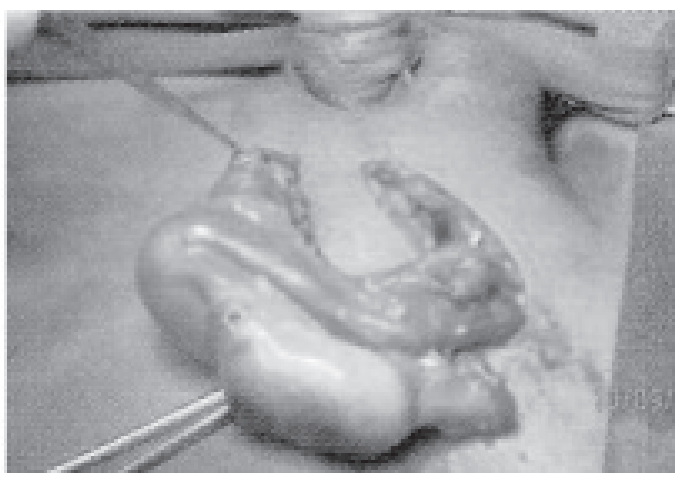

Fig.-2: Scrotal uterus \& ovary 


\section{Discussion:}

Assignment of sex in many cases is a technical, legal and a social challenge[1-3]. The factors that come in consideration to take the final decision are karyotype, feasibility of functional restoration, existing anatomy amenable to easy correction, psychological status in grownup patients, parents' desire, rehabilitation and sometimes intension of the operating surgeon[5-7]. Before psychosexualestablishmentof the patient, selection of gender by parents may play active role in final gender assignment. But in pubertal patients when opposite sex is planned, most of the occasions repeated and gradual psycho-sexual counseling become essential[4]. It is worth noting that karyotype is not the final or principal determinant of sex assignment although it is the main guide to offer a functional reproductive life[8]. To avoid surgical failure and to simplify the whole project, existing anatomy that permits easy and sustainable conversion have paramount importance. Interestingly, intension and experience of the surgeon sometimes come in discussion because it is found that andrologists have the intension to male and gynecological surgeons possess fascination to female type of assignment[9]. However, after all the successful technical steps, rehabilitation of this group of patients always remains as a big social liability.

\section{Conclusion:}

It is easy to assign sex in early life when reconstruction is needed. So all children born with ambiguous genitalia should be evaluated from endocrine point immediately and consulted with urologist or the assigned surgeon who can perform corrective surgery.

\section{References:}

1. Baskin LS, Ebbers MB: Hypospadias: Anatomy, etiology, and technique. J PediatrSurg 2006; 41(3): 463-472.

2. Lee PAet al: Consensus statement on management of intersex disorders. International Consensus Conference on Intersex. Pediatrics 2006; 118(2): e488-e500.

3. Greenspan'si Basic and Clinical Endocrinology, 8th ed. McGrawHill, New York, 2007, pp. 562-610.

4. Fallat ME, Donahoe PK: Intersex genetic anomalies with malignant potential. Curr Opin Pediatr 2006;18(3):305-311.

5. Kurzrock $E$ et al: Ontogeny of the male urethra: Theory of endodermal differentiation. Differentiation 1999;64:115-122.

6. McAleer IM, Kaplan GW: Is routine karyotyping necessary in the evaluation of hypospadias and cryptorchidism? J Urol 2001; 165 (6, Pt 1): 2029_ 2031; discussion 2031-2032.

7. De Castro R et al. Phalloplasty and urethroplasty in children with penile agenesis: Preliminary report. J Urol 2007; 177(3): 1112-1116; discussion 1117.

8. Jirasek $\mathrm{J}$ et al. The relationship between the development of gonads and external genitals in human fetuses. Am J Obstet Gynecol 1968; 101:830.

9. Kim KS et al. Expression of the androgen receptor and 5 alphareductase type 2 in the developing human fetal penis and urethra. Cell Tissue Res 2002; 307(2): 145-153. 